\title{
ATUAÇÃO DE GESTORES ESCOLARES NO CENÁRIO DE ENSINO REMOTO NO MUNICÍPIO DE ARARIPE/CE
}

http://dx.doi.org/10.5902/2318133866631

\author{
José Wellington Freire Rodrigues ${ }^{1}$ \\ Maria Elyara Lima de Oliveira²
}

\begin{abstract}
Resumo
Neste texto apresenta-se resultados de estudo pelo qual se buscou investigar a realidade enfrentada pelos gestores escolares do município de Araripe/CE em meio à pandemia da Covid19 e o cenário de ensino remoto emergencial. Delineou-se a partir de abordagem qualitativa de caráter exploratório, com coleta de dados por meio de questionários aplicados pela ferramenta Google Forms. A partir das análises efetivadas foi perceptível que os gestores escolares necessitaram efetivar a gestão democrática para garantir o funcionamento e a cooperação dos diferentes integrantes que fazem o processo educativo, pois o ensino remoto requereu trabalho conjunto, diálogo e parceria.

Palavras-chave: pandemia covid-19; gestores escolares; organização escolar; educação de qualidade.
\end{abstract}

\section{MANAGER'S ROLE IN E-LEARNING SCENARIO IN THE MUNICIPALITY OF ARARIPE/CE}

\section{Abstract}

This study sought to investigate the reality faced by school managers in the city of Araripe/CE amid Covid-19 pandemic and the emergency distance learning scenario. It was delineated from an exploratory research with qualitative nature, with data collection through questionnaires applied by Google Forms tool. From the analysis, it was noticeable that school managers needed more than ever to implement democratic management to ensure the functioning and cooperation of the different members who makes the educational process, as distance learning requires joint work, dialogue and partnership.

Key-words: covid-19 pandemic; school managers; school organization; quality education.

\footnotetext{
1 Universidade Regional do Cariri, Brasil. E-mail: wellington-ff@hotmail.com.

2 Instituto Federal de Educação, Ciência e Tecnologia do Sertão Pernambucano, campus Ouricuri, Brasil. Email: maria.elyara@ifsertao-pe.edu.br 


\section{Introdução}

m decorrência da pandemia de Covid-19 medidas preventivas tiveram que ser tomadas, o que modificou a forma como conduzimos a vida. $O$ isolamento social e o distanciamento mínimo foram ações cabíveis de profilaxia para evitar a disseminação desta infecção. Isso acarretou a paralisação das atividades comerciais, o trabalho em diversos setores da indústria e a escola.

Ante a esta nova realidade as pessoas tiveram que adaptar suas rotinas, a comunicação e o trabalho ganharam uma nova roupagem. Além disso, as tecnologias digitais de informação e comunicação assumiram um papel de destaque ao se colocarem como principal via para garantir a necessidade humana de interação social e comunicação, bem como o suporte para a realização dos trabalhos remotos em vários setores de nossa sociedade.

Dentre as áreas mais afetadas com esse novo cenário temos a instituição escolar. Desde meados de março de 2020 foram suspensas as aulas presenciais em todas as etapas e modalidades de ensino, ação que impactou diretamente 0 trabalho dos professores, gestores, secretários e demais profissionais ${ }^{3}$. Nesse novo contexto o trabalho conjunto e articulado da comunidade escolar é crucial para que o processo educativo seja possível. Tal realidade demandou, principalmente dos gestores, a elaboração de uma nova organização do trabalho escolar, visando à adequação aos padrões exigidos pela Organização Mundial da Saúde, o que culminou em ações tais como sistema de revezamento entre os funcionários que atuam na manutenção da infraestrutura escolar, orientação aos docentes sobre condução dos processos de ensino de forma remota, promoção de reuniões em plataformas online com funcionários e famílias para mobilizar o engajamento de todos na efetivação dos processos de ensino, dentre outras atividades.

Diante dessa conjuntura é que nos propomos a desenvolver esta investigação no sentido de contribuir para uma análise mais pontual sobre uma das instâncias que tem sido fortemente afetada por esse processo de reestruturação, que é o âmbito da gestão escolar. Para tanto, focamos especificamente na compreensão sobre a realidade do município de Araripe/CE, localizado na região do Cariri, Cento-Sul Cearense, na Chapada do Araripe. Este município, apesar de uma extensão territorial e demográfica pequena, conta com estruturas escolares que atendem a todas as etapas e níveis da educação básica, o que permite que seja possível analisar os impactos da reformulação e organização escolar provocada pelo cenário pandêmico, enfocando nas atribuições e exigências que se colocam para o exercício da gestão escolar. $O$ objetivo geral foi o de investigar a realidade do município no tocante ao trabalho do gestor escolar no cenário pandêmico.

A partir de abordagem qualitativa (Minayo, 2009), definiu-se como campo de estudo cinco escolas da rede pública do município de Araripe/CE, que atendem aos níveis de educação infantil, ensino fundamental e ensino médio e as modalidades de educação de jovens e adultos e educação profissionalizante. De cada uma destas instituições foi

\footnotetext{
3 O ensino remoto na educação básica e no ensino superior foi aprovado em caráter emergencial por vários dispositivos legais, emitidos pelo Ministério da Educação e pelo Conselho Nacional de Educação: a medida provisória $n$. 934, de 1ำ de abril de 2020, a portaria n. 544, de 16 de junho de 2020, parecer CNE/CP n. 05/2020, de 20 de maio de 2020, dentre outros. 
perscrutado um membro do núcleo gestor para responder a um questionário estruturado, composto de questões abertas, o que permite maior liberdade de expressão aos interlocutores. Participaram quatro diretores e uma coordenadora.

\section{A gestão escolar no cenário de pandemia: o município de Araripe/CE}

O contexto de ensino remoto, provocado pela pandemia da Covid-19 constitui-se um desafio a mais para que o processo de gestão democrática se consolide de acordo com a perspectiva proposta pelos dispositivos legais, pois exige ainda mais capacidade de liderança e cooperação por parte dos sujeitos que fazem o processo educativo continuar a ser efetivado, agora em espaços distintos e sem a proximidade física.

No município de Araripe/CE esta situação não foi diferente, as escolas e os gestores das instituições educativas desta localidade precisaram se adaptar a essa necessidade emergencial, o que implicou mudanças consideráveis na forma como a educação vinha sendo conduzida e, por conseguinte, no papel e atuação destes sujeitos. Para compreender melhor como vem sendo conduzidas estas alterações procedemos ao diálogo com os gestores de algumas das instituições educacionais que formam a rede municipal e estadual de ensino em tal localidade.

No âmbito da comunidade araripense a prática de gestão democrática é enfatizada pelo Plano Municipal de Educação (2015-2025), que enfatiza a necessidade de ampliação da participação da comunidade na construção de uma gestão democrático-participativa na escola. É importante destacar que quando se pensa na comunidade escolar entende-se que esta compreende não somente os profissionais que nela agem e atuam, mas também pais, alunos etc. Todos estes sujeitos devem atuar de forma conjunta em prol de uma melhor qualidade no desempenho educacional da escola:

Estimular o fortalecimento de conselhos escolares e conselhos municipais de educação, como instrumentos de participação e fiscalização na gestão escolar e educacional, inclusive por meio de programas de formação de conselheiros, assegurando-se condições de funcionamento autônomo (Araripe/PME, 2015, p. 58)

No âmbito da situação emergencial de pandemia, tornou-se premente a ação democrática por meio da comunidade escolar, mesmo com o distanciamento físico. $\mathrm{O}$ gestor escolar se coloca em meio a esse processo tentando construir e gerir as melhorias estratégias para que seja garantido ao menos o mínimo de qualidade nos processos educativos. Quando se pensa na realidade de um município como Araripe/CE, com índices demográficos e territoriais menores, torna-se ainda mais problemático pensar a possibilidade de efetivação do ensino remoto e mais do que isso, os desafios enfrentados pelos gestores.

A referida crise e a adoção do formato de ensino remoto demandaram dos alunos, professores, pais e gestores o acesso não só aos aparelhos eletrônicos - celulares, notebooks, tablets, etc. -, mas também aos serviços do provedor de internet e de plataformas digitais. Essa realidade gerou diversos desafios, principalmente para a gestão escolar, que além de aprender a lidar com tais recursos tecnológicos, ainda teve a responsabilidade de organizar e orientar a implantação do mencionado formato de ensino. 


\section{Formação e tempo de atuação na educação e na gestão escolar}

A formação dos profissionais de educação do Brasil tem um contexto histórico datado desde a década de 1930, com os cursos de formação de professores e especialistas em educação. Estes últimos, além de abarcar o exercício do magistério, enfocavam a profissionalização em administração e orientação escolar, inicialmente marcada pela cisão entre a formação de bacharelado e licenciatura, o que demarcava a formação de técnicos em educação e a formação de professores (Franco, 2014).

Ainda de acordo com Franco (2014) é somente com a LDB de 1996 que a formação para a gestão passou a ser ofertada de modo simultâneo a formação específica para o exercício docente, por meio dos cursos de Pedagogia e também a partir de cursos de especialização, no caso dos estudantes das licenciaturas específicas. Contudo, esses cursos de formação inicial para a atuação em gestão nem sempre conseguem contribuir para uma preparação mais sólida para o exercício da gestão, ademais, a experiência torna-se elemento essencial para que estes profissionais possam compreender de fato o que estes cargos exigem e, consequentemente, desempenhar o seu papel da melhor forma possível. Com base nesta percepção é que questionamos aos gestores, a priori, sobre sua formação e tempo de atuação na gestão.

Quadro 1 -

Formação e tempo de atuação na educação e na gestão.

\begin{tabular}{|c|c|c|}
\hline Nome & Formação & Tempo de atuação \\
\hline Lolita & Direito & 4 anos \\
\hline Poeta & Letras & Há 9 anos na escola, 2 anos na gestão \\
\hline Bella & Matemática & 6 anos na escola, 4 meses na gestão. \\
\hline Bravo & Letras & 2 anos \\
\hline Nina & Pedagogia & 15 anos na escola, 4 anos na gestão. \\
\hline
\end{tabular}

Fonte: autores.

A partir dos dados acima é possível perceber que alguns gestores, antes de adentrarem a este cargo na instituição de ensino, desenvolveram experiências e vivências na docência, com exceção de Lolita e Bravo, que não especificaram o tempo de atuação na docência e na gestão. Subtende-se que estes trabalham nas suas respectivas instituições no período que informaram compreendendo o trabalho de gestor como um ramo da educação.

\section{Gestão democrática e avaliações externas: conceitos, embates e perspectivas}

A gestão democrática é uma forma de organização e funcionamento que as comunidades escolares de uma instituição adotam para efetivar a participação no ambiente escolar. Essa vertente de gerenciamento e organização da vida escolar é apenas uma das muitas perspectivas que permeiam o ideário dos sujeitos que constituem as instituições de ensino brasileiras. Porém, é a gestão democrática que é preconizada nos dispositivos legais que direcionam o funcionamento destas instituições, o que denota um cenário de concepções que nem sempre se alinham. A partir de tal cenário e também 
no sentido de confrontar com os apontamentos sobre a formação inicial postos no item anterior é que buscamos entender melhor sobre as concepções de gestão escolar que estão presentes nas percepções e conceitos apresentados pelos gestores perscrutados, questionando: o que você compreende sobre gestão democrática?

A esta indagação Lolita afirmou que "é uma gestão participativa, que conta com a atuação de organismos colegiados como conselho escolar, grêmio estudantil, onde as questões são tratadas e decididas de forma coletiva", ou seja, revela uma percepção clara sobre o que significa a gestão democrática. A perspectiva de Lolita coaduna com a de Nina, que ressalta: "Gestão democrática é aquela onde a comunidade escolar participa como sujeito ativo nas decisões da escola". Isso remete a uma questão proposta por Lück (2006), segundo a qual participação e democracia não se desvinculam, sendo conceitos complementares. Como se percebe, as duas gestoras tomam por base essa vertente que visa a alinhar estes dois conceitos essenciais ao bom funcionamento de uma instituição de ensino e aos dispositivos legais mencionados anteriormente.

Estas manifestações pressupõem ainda que os sujeitos que compõem a estrutura escolar precisam ter clareza das concepções teóricas e filosóficas que orientam 0 exercício da gestão democrática, tendo em vista que estes ideais se expressam na rotina escolar, influindo direta e indiretamente na relação harmônica ou não vivenciada pelos que compõem a escola. Compreensão expressa na fala de Poeta, que ressalta: "Quando para a tomada de decisões é considerada a participação dos diversos atores envolvidos no processo de ensino e aprendizagem". Esta vertente complementa-se com a visão de Bravo: "Compreende administração participativa envolvendo todos os envolvidos no processo de ensino aprendizagem".

Os processos de ensino e aprendizagem, retratado nas manifestações dos diretores é visto como a troca de informações necessárias para que o aluno possa aprender. Uma relação que se trava não somente entre professores e alunos, mas é permeada pela participação da gestão. Posição que converge com a compreensão da coordenadora Bella: "Compreendo que a gestão democrática contribui bastante para o alcance de uma aprendizagem mais significativa para o aluno. Pois o processo de ensino aprendizagem deve contar com a participação de toda a comunidade escolar". Igualmente depreende-se que a gestão articula e organiza as demandas necessárias para que docentes e discentes tenham condições de cumprir horários, tarefas e informações necessárias, além de fornecer subsídios para suas práticas pedagógicas.

Nesse cenário pandêmico os gestores encontram-se em meio a desafios e impasses constantes, tanto no ensino, quanto na efetivação de um trabalho democrático, pois tanto as instituições, quanto os gestores, são cobrados e responsabilizados pelos índices escolares do corpo estudantil. Objetivo que se depara com muitas dificuldades para ser efetivado, dentre elas: o fato de muitos alunos não terem acesso à internet de qualidade, não disporem de aparelhos eletrônicos, sem falar naqueles que sentem dificuldades em manusear os aparatos tecnológicos, não conseguindo acompanhar de forma coerente esse novo formato de aulas.

Essa realidade pode repercutir em baixos índices de rendimento por parte dos estudantes, das escolas e, consequentemente, da ação efetuada pelos gestores. Este contexto se evidencia de forma mais nítida por meio das avaliações externas, que buscam auxiliar o poder público na detecção de problemas ou fragilidades na educação escolar, e

\begin{tabular}{|l|l|l|l|l|r|}
\hline Regae: Rev. Gest. Aval. Educ. & Santa Maria & v. 10 & n. 19 & e66631, p. 1-16 & 2021 \\
\hline
\end{tabular}


em contrapartida, acabam por se configurar também, como instrumentos de responsabilização dos docentes, das instituições e dos gestores que ali atuam. Sobre esta perspectiva avaliativa questionamos aos gestores: como você se sente com a realização das avaliações externas? E esse ano como ficou essa questão? Quais as orientações da Seduc neste sentido?

Quadro 2 -

Avaliações externas e gestão escolar.

\begin{tabular}{|c|l|}
\hline Nome & \multicolumn{1}{c|}{ Resposta } \\
\hline Lolita & $\begin{array}{l}\text { Acredito que são úteis para fins de diagnóstico e de pensar e implantar } \\
\text { políticas públicas que melhorem a educação. Anualmente temos o Spaece, } \\
\text { o qual foi suspenso esse ano. }\end{array}$ \\
\hline Poeta & $\begin{array}{l}\text { Nossa instituição, à revelia de todas as dificuldades e desafios próprios } \\
\text { desse momento de pandemia, continua com suas atividades escolares, em } \\
\text { ensino remoto, com vistas ao desenvolvimento das aprendizagens } \\
\text { necessárias para o Enem e vestibulares. A avaliação do Spaece, } \\
\text { excepcionalmente este ano, não será aplicada. }\end{array}$ \\
\hline Bella & $\begin{array}{l}\text { As avaliações externas sem dúvida, são muito válidas porque mostram um } \\
\text { panorama geral do nível de aprendizagem dos estudantes. Esse ano não } \\
\text { serão realizadas avaliações externas, estas foram canceladas por conta da } \\
\text { Pandemia do Coronavírus. A Seduc tem orientado que o trabalho } \\
\text { pedagógico continue com foco na qualidade do ensino para que o } \\
\text { educando consiga desenvolver as competências e habilidades prioritárias, } \\
\text { independente da realização ou não das avaliações externas. }\end{array}$ \\
\hline Bravo & $\begin{array}{l}\text { Esse ano, por ocasião da pandemia, as escolas foram dispensadas dessas } \\
\text { avaliações. Foi um ano complicado, no qual nossos alunos tiveram muito } \\
\text { prejuízo no tocante a aprendizagem. Estamos prevendo um retrocesso } \\
\text { nesse sentido, inviabilizando a aplicação desse tipo de avaliação. }\end{array}$ \\
\hline
\end{tabular}

Fonte: autores.

É possível perceber que Lolita e Bella entendem que as avaliações externas têm como características avaliar o nível de aprendizagem dos estudantes e determinar políticas públicas para a melhoria da educação. Bravo e Poeta não deixam evidentes as suas percepções, porém, Poeta destaca que a escola tem se voltado para aprendizagens necessárias para vestibulares e Exame Nacional do Ensino Médio, auxiliando os estudantes nesse sentido. Contudo, Bravo discute o quão dificultoso tem sido o ensino mediante a pandemia, pois as dificuldades e desafios são muitos para os estudantes.

A avaliação do Spaece foi cancelada no ano de 2020, por conta da pandemia. Por unanimidade os referidos gestores corroboram com essa decisão, o que deixa evidente a preocupação com o risco de contaminação dos discentes e funcionários. Porém, manifestam que uma das principais dificuldades encontradas neste cenário pandêmico é sem dúvida manter a qualidade da educação. 
As demandas por uma educação de qualidade, mesmo com os impasses gerados, não deixaram de acontecer. Sobre isto Nina revelou certa pressão pelos resultados positivos no ensino, ressaltando que, mesmo nesse cenário, foi realizada uma avaliação de forma presencial, junto ao público de crianças de cinco anos:

"No pré-escolar, cinco anos, as crianças realizam apenas a avaliação do Sisam (sistema de avaliação municipal). Mesmo diante do cenário atual o qual nos encontramos os educandos da nossa creche realizaram a avaliação do Sisam de forma presencial, para averiguarmos melhor o desenvolvimento da criança e assim concluir o diagnóstico anual com mais precisão. Ressalto, que obedecemos às recomendações da OMS e separamos as turmas por salas, horários e dias marcados e com número de alunos reduzidos. A Seduc nos orienta a avaliar o desenvolvimento do educando de forma diagnóstica, de forma descritiva."

O sistema de avaliação municipal - Sisam - foi realizado por determinação da Seduc e a escola de educação infantil referida conta com 90 alunos distribuídos em dois turnos, manhã e tarde. Por este motivo a instituição teve capacidade de realizar esta avaliação em dias diferentes e horários marcados.

\section{Gestão escolar e sua efetivação no contexto de ensino remoto}

O trabalho do gestor encontra muitos percalços nas atividades diárias da instituição, algo que se ampliou ainda mais nesse cenário da pandemia. Dentre as demandas acrescidas aos profissionais da educação e equipes gestoras estão a necessidade de se adequar ao uso das TDICs para efetivação do ensino de forma remota. Contexto que se agrava devido ao fato de que muitos destes profissionais ainda encontram bastante despreparo técnico para saber operar as ferramentas digitais, sem contar na própria demanda estrutural, tendo em vista que tanto gestores, como docentes, discentes e famílias enfrentam a dificuldade de acesso aos aparelhos tecnológicos e também dispor de uma internet de qualidade.

$\mathrm{Na}$ tentativa de atenuar essas dificuldades o governo do Estado do Ceará distribuiu chips de dados móveis 3G/4G com pacotes de 20 GB para possibilitar àqueles alunos de famílias carentes que fazem parte da rede estadual de educação pública o acesso as aulas na modalidade remota. A medida visou a atender 347 mil estudantes, nos diversos níveis e modalidades de ensino da educação básica:

Isso significa oportunidade para os nossos jovens aprender mais, estudar mais e cada vez mais a gente ter orgulho. A única forma de reduzir as desigualdades é dar educação pública de qualidade. Acreditamos no poder da educação na transformação das pessoas (Seduc, 2020, n.p).

Essa medida emergencial se mostrou como uma ação de relevante importância. Contudo, é preciso considerar que apenas amenizou as dificuldades já expostas e não conseguiu contemplar uma parcela da população estudantil que não possui aparelhos celulares e dispositivos móveis. Realidade que fica ainda mais acentuada quando se trata dos estudantes de zona rural, onde muitas vezes o sinal da rede móvel é precário. Dados 
de pesquisa realizada pelo Instituto de Pesquisa Econômica Aplicada (Ipea, 2020) mostram o quão alarmante é a situação de muitos estudantes no que se refere as suas possibilidades de acompanhamento do ensino remoto:

Seis milhões de estudantes brasileiros, da pré-escola à pós-graduação, não dispõem de acesso domiciliar à internet em banda larga ou em rede móvel 3G/4G para acompanhar aulas e outras atividades online. Destes, cerca de 5,8 milhões frequentam instituições públicas de ensino no país. (p. 53)

Ante a tal realidade buscamos compreender como os gestores perscrutados estão pensando e enfrentando tais obstáculos. Para tanto questionamos: como tem sido o trabalho do gestor escolar nesse cenário de pandemia? Quais as dificuldades enfrentadas no exercício da gestão nesse cenário? Ao se posicionar sobre o assunto Lolita (2020) e Bravo (2020), respectivamente, descreveram:

"Desafiador. Tivemos que adequar o ensino presencial para o ensino remoto em meio a falta de acesso, equipamentos e formação, os quais fomos adquirindo no decorrer do ano, bem como participando de formações."

"Tem sido desafiador porque o gestor tem a responsabilidade de dar suporte aos professores e alunos em meio a realidade do ensino a distância."

Vê-se que ambos manifestaram que esse período tem sido muito desafiador, gerando para o gestor uma sobrecarga e responsabilidade ainda maior. Mesmo estando em processo de aprendizagem e adaptação ao formato de ensino remoto, estes precisam fornecer o suporte necessário aos impasses encontrados nas atividades pedagógicas, mediando conflitos e criando estratégias para viabilizar o melhor andamento do processo de ensino e aprendizagem. Lolita enfatizou a necessidade de formação e aperfeiçoamento, tanto para elas, quanto para os docentes em relação ao uso das TDIC. Deixando claro que mesmo sendo uma exigência que vem se colocando há alguns anos para o exercício da docência, muitos educadores ainda se sentem despreparados.

Esta crise explicitou de forma mais incisiva essa necessidade de adequação as exigências advindas das mudanças estruturais, políticas e sociais que nossa organização societária vem vivenciando, revelando um ponto positivo em meio a esse contexto, o fato de que instituições, gestores, educadores e famílias precisaram se reinventar e buscar soluções criativas para que o ensino aconteça.

É justamente nesse viés que Poeta se posicionou: "Tem sido bem desafiador e cansativo. Mas também de muita criatividade e aprendizado. Posso dizer que tem sido um ano propício para o desenvolvimento de habilidades socioemocionais". Neste mesmo sentido Bella e Nina afirmaram, respectivamente: "O trabalho tem sido árduo e muito desafiador, sendo necessário nos reinventarmos dia após dia". "Um desafio! Um aprendizado! Pois não esperávamos que um vírus mudaria de forma tão radical a nossa rotina". 
No intuito de entender mais detalhadamente como se colocam estas dificuldades para o exercício da atividade gestora na atual conjuntura perguntamos: quais as dificuldades enfrentadas no exercício da gestão nesse cenário?

Quadro 3 -

Dificuldades encontradas para o exercício da gestão no cenário de ensino remoto.

\begin{tabular}{|c|l|}
\hline Nome & Resposta \\
\hline Lolita & $\begin{array}{l}\text { Posso citar a falta de acesso à internet, falta de equipamentos, } \\
\text { organização/adaptação do tempo de estudo dos alunos por meio remoto. }\end{array}$ \\
\hline Poeta & $\begin{array}{l}\text { Falta de acesso à internet e do próprio aparelho celular e/ou computador. } \\
\text { Além da desmotivação e desinteresse pela escola. }\end{array}$ \\
\hline Bravo & $\begin{array}{l}\text { Temos como principal dificuldade a precariedade do acesso às } \\
\text { tecnologias pelas famílias. }\end{array}$ \\
\hline Nina & $\begin{array}{l}\text { A dificuldade maior foi adaptar-se ao mundo amplo da tecnologia que hoje } \\
\text { temos a obrigatoriedade de conviver mais perto com ele. }\end{array}$ \\
\hline
\end{tabular}

Fonte: autores.

É possível notar, nas manifestações dos entrevistados, que muitos são os desafios para a efetivação do ensino remoto. Bella (2020) ressaltou a dificuldade de se atender todos os alunos no ensino remoto: "A nossa maior dificuldade é conseguir chegar e atender a todos os alunos nesse formato de aulas remotas. Principalmente por conta da distância entre a residência do aluno e a escola". A gestora deixou claro que, além dos outros entraves que já enfatizamos, ainda surgiu a demanda relacionada a distância de acesso as residências dos estudantes que moram em localidades mais longínquas e de difícil acesso, fator que demandou a capacidade de mobilizar a equipe escolar a buscar soluções em conjunto, bem como a realizar uma distribuição das tarefas entre funcionários e docentes de modo que possam encontrar juntos saídas para auxiliar os alunos e continuar cumprindo seu papel de democratização do ensino.

Ao saber quais as dificuldades encontradas no exercício da gestão neste cenário pandêmico, se faz pertinente também conhecer a realidade do ensino remoto para o corpo docente, por esta razão foi perguntado: como foi a receptividade dos professores para a realização do trabalho no formato remoto?

Quadro 4 -

Receptividade docente no formato de ensino remoto.

\begin{tabular}{|l|l|}
\hline Nome & \multicolumn{1}{|c|}{ Resposta } \\
\hline Lolita & $\begin{array}{l}\text { Os professores se engajaram, participaram de formações sem resistência, } \\
\text { assim como se esforçaram de forma individual para continuar ensinando e } \\
\text { mediando a aprendizagem, apesar das dificuldades e do cenário de incertezas e } \\
\text { ansiedade. }\end{array}$ \\
\hline Poeta & $\begin{array}{l}\text { Ficaram apreensivos, à priori. Mas em seguida todos se mostrarem abertos e } \\
\text { receptivos a proposta. A escola deu todo o apoio formativo necessário. }\end{array}$ \\
\hline
\end{tabular}




\begin{tabular}{|c|l|}
\hline Bella & $\begin{array}{l}\text { Todos reagiram inicialmente, com muita preocupação, insegurança e incerteza. } \\
\text { Demonstravam medo de não conseguir desempenhar seu trabalho nesse novo } \\
\text { formato. }\end{array}$ \\
\hline Bravo & $\begin{array}{l}\text { Foi muito positiva! Nossos professores abraçaram a causa e demonstraram } \\
\text { muito criatividade e capacidade de improviso. }\end{array}$ \\
\hline
\end{tabular}

Fonte: autores.

Considerando as declarações dos gestores acima, infere-se que o ensino remoto emergencial se colocou como uma ação que surpreendeu não somente a população de modo geral, mas principalmente os profissionais da educação. Fato que revelou forte despreparo por parte das instituições de ensino, dos professores e gestores, em relação ao manuseio das tecnologias. Sobre isto percebe-se simultaneamente no posicionamento dos gestores que os docentes de cada instituição, de início, sentiram-se com dificuldades e tiveram receio de utilizar esse formato de ensino, o que coaduna com a reflexão de Sousa (2020): "O ensino remoto tornou-se um desafio para esses profissionais que precisaram aprender na prática a usar as TIC para desenvolver as suas aulas. $\mathrm{O}$ ensino remoto provocou um aumento do nível de ansiedade dos professores, além de sobrecarga de trabalho" (p. 113).

É possível afirmar que houve um processo de adaptação a esse novo formato de ensinar. Essa reformulação exige dos professores e gestores, não somente estar abertos a novas perspectivas metodológicas, mas também, rever suas concepções teóricas e epistemológicas sobre o que é educar, principalmente na sociedade da informação e da dinamicidade constante. Ademais, é necessário considerar ainda, que esse percurso de adaptação tem revelado por outro lado, uma situação de intensa sobrecarrega, devido a excessiva demanda de trabalho e difícil separação entre o ambiente de trabalho e o lar, o que pode implicar em problemas psicológicos futuros para estes profissionais.

A atuação da gestão sob a organização e o apoio ao corpo docente é algo que pode ser fator crucial para que os professores possam desempenhar seus papéis com mais facilidade, à medida que veem no gestor um apoio e uma figura de partilha e cooperação nesse processo. Este elemento é perceptível na declaração de Poeta, ao mencionar que a escola prestou total apoio aos seus docentes neste percurso de aulas remotas. Nina apontou na mesma direção:

"De início foi complicado, nenhum dos professores tinha afinidade com as tecnologias e isso gerou um medo de não conseguir adaptar-se ao novo. Porém, com a parceria família e escola e a troca de experiência entre os professores, o apoio da gestão e da secretaria de educação, o medo cessou e o trabalhou foi realizado com sucesso."

É preciso refletir ainda sobre a realidade do público para o qual estas estratégias vêm sendo pensadas: os estudantes. No ensejo de encontrar respostas sobre a realidade dos discentes questionamentos aos gestores: a clientela escolar possui acesso as plataformas digitais para que possam dar continuidade aos estudos de forma remota? Se não possuem, o que tem sido feito? 
Quadro 5 -

Acesso as plataformas digitais pelo corpo estudantil.

\begin{tabular}{|c|l|}
\hline Lome & \multicolumn{1}{c|}{ Respostas } \\
\hline Lolita & $\begin{array}{l}\text { A Seduc disponibilizou o Google classroom, além do Conexão Seduc e o } \\
\text { aluno online que já existiam. }\end{array}$ \\
\hline Poeta & $\begin{array}{l}\text { A seduc disponibilizou e-mail para cada um dos alunos para que estes } \\
\text { tivessem acesso ao Google sala de aula, Google meet, Google formulários... }\end{array}$ \\
\hline Bella & $\begin{array}{l}\text { Grande parte da clientela possui acesso à internet e às plataformas digitais. } \\
\text { Outra parcela importante, infelizmente não possui esse acesso. Para os que } \\
\text { não possuem acesso a escola disponibiliza e faz a entrega aos alunos das } \\
\text { orientações das aulas e atividades no formato impresso. }\end{array}$ \\
\hline Bravo & $\begin{array}{l}\text { Nem todos possuem aparelho celular e, mesmo os que têm, não possuem } \\
\text { acesso à internet. Temos organizado materiais impressos e feito a } \\
\text { distribuição em domicílio. }\end{array}$ \\
\hline
\end{tabular}

Fonte: autores.

$\mathrm{Na}$ educação pública muitos estudantes têm dispositivos móveis e aparelhos eletrônicos para acesso à internet, o que viabiliza alcance as plataformas digitais para cumprir com aulas e atividades remotas, porém uma grande maioria não conta com estas mesmas condições. As dificuldades são inúmeras, porém, os gestores ressaltaram que tiveram apoio da Seduc, principalmente porque esta buscou auxílio junto ao governo do Estado do Ceará no sentido de criar medidas que permitissem aos estudantes terem acesso as plataformas digitais. Conforme Lolita a instituição que ela atua pode dispor ainda de algumas ferramentas para os alunos, além do Conexão Seduc ${ }^{4}$, que teve por objetivo promover a conexão entre os educadores e os discentes. Poeta também destacou a criação de e-mails institucionais para que os discentes pudessem acessar plataformas como: Google Meet, Google Classroom e Google Forms.

Porém, mesmo com todas as ações, grande parcela dos estudantes ainda não possui acesso à internet ou a dispositivos eletrônicos. Este fato evidencia-se nas manifestações de Bella e Bravo. Contexto que revela os limites do ensino remoto e a necessidade de se pensar políticas que democratizem a inserção digital destes discentes, haja vista o fato de que o cenário pandêmico só deflagrou uma necessidade que já colocava há muitos anos.

Como forma de amenizar as consequências da dificuldade de acesso de muitos alunos, Bella e Bravo ressaltam que foi traçada a seguinte estratégia: adaptar as atividades a roteiros escritos e impressão dos mesmos para que fossem entregues nas residências dos estudantes. Ação que exigiu dos gestores e da comunidade escolar ainda maior exercício na tomada de decisões democráticas, na distribuição de tarefas e do empenho de todos para viabilizar a execução de tais processos. Haja vista, o fato de que os discentes advêm de localidades as mais variadas possíveis, o que requer muito planejamento e dedicação para efetivar a entrega das atividades aos mesmos.

4 Espaço formativo aberto em plataforma digital que busca por meios de webconferências, reuniões estabelecer vínculos comunicacionais e trocas de informação entre os docentes, auxiliando em planos, projetos e o uso de plataformas digitais e ambientes colaborativos de aprendizagem.

\begin{tabular}{|l|l|l|l|l} 
Regae: Rev. Gest. Aval. Educ. & Santa Maria & v. 10 & n. 19 & e66631, p. $1-16$
\end{tabular} 
Nina afirmou que os alunos têm acesso apenas a dispositivos móveis como celular, o que possivelmente facilita a comunicação e o desenvolvimento de atividades remotas:

"A clientela deste ano na nossa creche só tem acesso ao whatsapp. Criamos grupos por salas, onde as professoras postavam as atividades e a família fazia a devolutiva por meio de fotos e em alguns momentos vídeos. As famílias que não tinham acesso faziam a entrega das atividades e orientávamos os pais ou responsável de forma presencial. Ressalto que as atividades mesmo para quem estavam nos grupos eram entregues impressas a cada quinze dias. Nestes encontros era feito a correção das atividades, e as intervenções que fossem necessárias."

A realidade expressa acima é igualmente relatada por Bella e Bravo. Desta feita, denota-se que para o funcionamento adequado do ensino remoto necessita-se não somente de uma gestão articulada, mas de igual modo, do apoio das famílias dos educandos, fator fundamental para a comunicação e auxílio dos discentes. Diante disso, é que realizamos a seguinte indagação aos gestores: como está sendo a relação com as famílias? Obtivemos as seguintes respostas:

Quadro 6 -

Relação com as famílias.

\begin{tabular}{|c|l|}
\hline Nome & \multicolumn{1}{|c|}{ Respostas } \\
\hline Lolita & $\begin{array}{l}\text { Realizamos as reuniões com as famílias bimestralmente por meio de } \\
\text { videoconferência, conversamos pelo whatsapp e procuramos manter o vínculo } \\
\text { durante esse período por meio do diálogo, da empatia, da escuta de forma } \\
\text { tranquila e participativa. }\end{array}$ \\
\hline Poeta & $\begin{array}{l}\text { Muito desafiadora devido à grande extensão territorial do município e a falta de } \\
\text { acesso à internet. }\end{array}$ \\
\hline Bella & $\begin{array}{l}\text { A escola tem buscado, na medida do possível, manter uma parceria com as } \\
\text { famílias e certa proximidade ainda que virtualmente, objetivando que mesmo } \\
\text { diante dessa situação difícil, os estudantes sintam-se estimulados a dar } \\
\text { seguimento aos seus estudos e que também não percam o vínculo com a } \\
\text { escola. E neste sentido a família faz toda diferença. }\end{array}$ \\
\hline Bravo & $\begin{array}{l}\text { Não muito boa! No atual contexto pandêmico, esperávamos uma maior } \\
\text { colaboração da família no auxílio aos nossos alunos. }\end{array}$ \\
\hline Nina & $\begin{array}{l}\text { Mesmo diante dessa pandemia que assola o mundo, a relação família e escola } \\
\text { estão em uma constante sintonia, uma relação de parceria tendo como objetivo } \\
\text { principal o pleno desenvolvimento da criança, onde propiciamos ao educando } \\
\text { uma segurança na aprendizagem. }\end{array}$ \\
\hline
\end{tabular}

Fonte: autores.

A família é fator fundamental na formação dos sujeitos, pois esta é em primeira instância de educação, acolhimento e cuidado. Por sua vez, as primeiras relações sociais estabelecidas entre o educando e a escola são mediadas pela instância familiar e assim 
ocorre ao longo da vida escolar de cada indivíduo. Porém, algumas famílias participam mais ativamente que outras, e este aspectos podem repercutir diretamente no desenvolvimento de propostas e atitudes no atual cenário que vivemos.

Neste sentido não se pode pensar na educação dos sujeitos sem uma boa relação entre essas duas instituições, que "compartilham a tarefa de preparar as crianças e os jovens para a inserção crítica, participativa e produtiva na sociedade" (Reali; Tancredi, 2005 , p. 240). Sobre isto os posicionamentos dos sujeitos participantes da pesquisa divergem em alguns pontos. Para Lolita a gestão atua a todo o momento de forma pacífica e harmônica estabelecendo sempre diálogos com as famílias. Já para Poeta tem sido uma relação desafiadora, dadas as questões territoriais do município, pois muitos pais advêm da zona rural e não tem acesso à internet, o que dificulta bastante a comunicação.

Bella ressaltou que a participação da família é fundamental para que os estudantes não percam o vínculo com a escola e que a instituição está buscando fazer cumprir seu papel social na formação dos cidadãos. Assim, sua experiência com a relação familiar tem sido de parceria, construindo ações para que o estudante tenha motivação para continuar tendo êxito no processo de aprendizado.

Sobre isto Bravo destacou que esta relação não se concretiza como harmônica em meio à pandemia, o que pode contribuir para que alguns dos objetivos escolares não sejam contemplados. Já Nina afirmou que o trabalho e a parceria da instituição com a família estão voltados para o desenvolvimento da criança, o que corrobora com os apontamentos de Polonia e Dessen (2005, p. 304) "quando a família e a escola mantêm boas relações, as condições para um melhor aprendizado e desenvolvimento da criança podem ser maximizadas".

Apesar das dificuldades do período de pandemia, a relação entre escola e família é necessária para a construção de relações sociais que permeiam todas as esferas societárias e para a construção de aprendizagens significativas para os estudantes que vão além dos espaços escolares. Um dos aspectos de importante atuação da gestão escolar democrática é conseguir estabelecer e manter boas relações com todos os componentes que constituem a escola, principalmente com as famílias. É importante considerar que as famílias precisaram aproximar-se ainda mais das escolas. Essa comunicação e parceira se configura como elemento essencial para que ocorra um processo de acompanhamento e desenvolvimento adequado por parte dos discentes. Porém, nem sempre há essa clareza por parte da dimensão familiar. Desta forma, é possível pensar que se colocou para os gestores escolares uma necessidade mais premente por criar estratégias no sentido de ampliar os laços de diálogo e parceria com os pais e responsáveis. Para tanto, a elaboração de metas e ações conjuntas pela comunidade escolar faz-se fundamental para a efetivação de estratégias nesse sentido. Somente assim é possível pensar na garantia de mínima qualidade para o ensino do formato remoto. 


\section{Considerações finais}

Os dados analisados nos permitiram perceber que mesmo se tratando de um município de extensão territorial e demográfica pequena, são muitas as dificuldades

enfrentadas pelos gestores perscrutados e o quão complexo tem sido para a efetivação não somente de uma gestão na perspectiva democrática, como também de um ensino de qualidade em meio as ações remotas.

Os profissionais da educação têm enfrentado um árduo trabalho, à medida que se percebe que de um lado os docentes precisam lidar com duplas e talvez triplas jornadas de trabalho, ainda mais exaustivas em formatos remotos. De outro, os gestores precisam articular a comunidade escolar, organizar o processo de ensino, auxiliar e planejar ações em consonância com os professores, demais funcionários das escolas e com as famílias dos estudantes.

Outrossim, não somente os professores, mas também os gestores precisaram lidar com as TDIC, manter-se emocionalmente equilibrado, auxiliar e preparar os docentes para a utilização de ferramentas digitais, fortalecer a relação com os familiares, pensar estratégias para lidar com as disparidades sociais dos estudantes que não possuem acesso à internet, dentre tantos outros obstáculos que vem se colocando

De modo geral, percebe-se que as escolas públicas do município de Araripe/CE e os gestores perscrutados, mesmo com todas as dificuldades impostas, tem buscando se manter firmes na busca por construir um trabalho educativo por meio da gestão democrática.

\section{Referências}

ARARIPE. Plano municipal de educação 2015-2025. Disponível em: https://www.cmararipe.ce.gov.br/leis.php. Acesso em: 12 set, 2020.

BRASIL. Lei n. 9.394, de 20 de dezembro de 1996: estabelece as diretrizes e bases da educação nacional. Brasília: Senado Federal, 1996.

BRASIL. Lei n. 13.005, de 25 de junho de 2014: aprova o Plano Nacional de Educação PNE e dá outras providências. Brasília, 25 jun. 2014. Disponível em: http://www.planalto.gov.br/ccivil_03/_ato2011-2014/2014/lei//13005.htm. Acesso em 8 abr. 2021.

BRASIL. Constituição da República Federativa do Brasil. Brasília: Senado Federal, 1988.

BRITO, Glaucia da Silva. Inclusão digital do profissional professor: entendendo o conceito de tecnologia. ENCONTRO ANUAL DA ANPOCS, 30, 2006. Anais ... Caxambu: Anpocs, 2006.

FRANCO, Alexandre de Paula. A formação dos gestores escolares nos cursos de pedagogia. São Paulo: USP, 2014. 323f. Tese (Doutorado em Educação). Faculdade de Educação, Universidade de São Paulo.

GONSALVES, Elisa Pereira. Iniciação à pesquisa científica. Campinas: Alínea, 2003.

IPEA. Ipea analisa estratégias para universalizar o ensino remoto na pandemia. 2020. Disponível

em: https://www.ipea.gov.br/portal/index.php?option=com_content\&view=article\&id=36560\&lte mid=9. Acesso em 9 jan. 2021. 
LIBÂNEO, José Carlos; OLIVEIRA, João Ferreira de; TOSCHI, Mirza Seabra. Educação escolar: políticas, estrutura e organização. São Paulo: Cortez, 2012.

LÜCK, Heloísa. A gestão participativa na escola. Petrópolis: Vozes, 2006.

Disponível em <www.tvebrasil.com.br/salto>. Acesso em 12 out 2020.

LÜCK, Heloísa. A gestão pedagógica da organização curricular com foco na superação da distorção idade-série. Gestão em Rede, n. 62, 2005, p. 10-14.

LÜCK, Heloísa. Gestão da cultura e do clima organizacional da escola. Petrópolis: Vozes, 2011.

MARCONI, Maria de Andrade; LAKATOS, Eva Maria. Fundamentos de metodologia científica. São Paulo: Atlas, 2003.

MINAYO, Maria Cecília de Sousa de (org.). Pesquisa social: teoria, método e criatividade. Rio de Janeiro: Vozes, 2009.

MORAN, José Manuel. A Educação que desejamos: novos desafios e como chegar lá. Campinas, SP: Papirus, 2007.

NOGUEIRA, Ana Maria e BERNARDES, Hila Maria Rodrigues. Formação em serviço de gestores das escolas públicas: o projeto da Cefeb para as escolas públicas municipais no Ceará. SEMINÁRIO NACIONAL DE POLÍTICA E GESTÃO DA EDUCAÇÃO, 2011. Anais ... Itabaiana: UFS, 2011.

PARO, Vitor Henrique. Eleição de diretores: a escola pública experimenta a democracia. São Paulo: Xamã, 2003.

POLONIA, Ana da Costa; DESSEN. Maria Auxiliadora. Em busca de uma compreensão das relações entre família e escola. Psicologia Escolar e Educacional, São Paulo, v. 9, n. 2, 2005, p. 303-312.

REALI, Aline Maria de Medeiros Rodrigues; TANCREDI, Regina Maria Simões Puccinelli. A importância do que se aprende na escola: a parceria escola-famílias em perspectiva. Paidéia, Ribeirão Preto, v. 15, n. 31, 2005, p. 239-247.

SEDUC. Governo destina chips com internet móvel para 347 mil alunos de escolas e universidades. 2020. Disponível em: https://www.seduc.ce.gov.br/2020/11/09/governodestina-chips-com-internet-movel-para-347-mil-alunos-de-escolas-e-universidadesestaduais/ Acesso em: 27 dez. 2020.

SILVA, Luciana Pereira. A utilização de recursos tecnológicos no ensino superior. Revista Olhar Científico, Instituto de Ensino Superior de Rondônia, v. 1, n. 2, 2010, p. 267-285.

SOUZA, Elmara Pereira de. Educação em tempos de pandemia: desafios e possibilidades. Cadernos de Ciências Sociais Aplicadas, Vitória da Conquista, v. 17, n. 30, 2020, p. 110-118.

VIEIRA, Sofia Lerche. Gestão, avaliação e sucesso escolar: recortes da trajetória cearense. Estudos Avançados, São Paulo, v. 21, n. 21, 2007, p. 45-60.

José Wellington Freire Rodrigues é professor na Escola Antônio Alexandrino de Alencar.

Orcid: https://orcid.org/0000-0002-5389-8606.

Endereço: Rua Padre Nelson, 125 - 63170-000 - Araripe - CE - Brasil.

E-mail: wellinngton-ff@hotmail.com. 
Maria Elyara Lima de Oliveira é professora no Instituto Federal do Sertão Pernambuco.

Orcid: http://orcid.org/0000-0001-5928-2303.

Endereço: Estrada do Tamboril, S/N - 56200-000 - Ouricuri - PE - Brasil.

E-mail: maria.elyara@ifsertao-pe.edu.br.

Critérios de autoria: Wellington pensou na temática, onde pesquisar e quais aspectos abordar e Elyara elaborou a estrutura para o artigo, sobre o que pesquisar e quais referências bibliográficas consultar, orientando a pesquisa. Wellington realizou a coleta de dados e fez a análise dos mesmos, junto com Elyara, que direcionou a melhor forma de discussão e embasamento teórico para cada aspecto do texto. Os autores, em consonância, trabalharam no planejamento do artigo, revisando o assunto abordado em suas características estruturais e linguísticas.

Recebido em 7 de julho de 2021.

Aceito em 27 de outubro de 2021.

cc) (i) (3) $\ominus$ 